\title{
Crianças pequenas brincando em creche: a possibilidade de múltiplos pontos de vista
}

\author{
Cleido Roberto Franchi e Vasconcelos \\ Maria Clotilde Rossetti Ferreira \\ Universidade de São Paulo
}

\begin{abstract}
Resumo
Este trabalho surgiu como um foco secundário de uma pesquisa sobre interação criança-criança. Nesse estudo é proposto um meta-olhar sobre o fazer do pesquisador, analisando o próprio "coletar dos dados", com a idéia de que os dados não são dados, mas construídos na interação entre a rede de significações do pesquisador e os eventos no aqui-e-agora da situação observada. Assim, partindo do pressuposto da incapacidade estrutural humana de um acesso a uma realidade externa independente (Maturana \& Varela), este segundo foco de pesquisa delimita três perspectivas diversas sobre os "dados coletados", a serem igualmente consideradas: 1) a perspectiva do pesquisador; 2) a das educadoras envolvidas no cuidado das crianças; 3) a das próprias crianças. Essas perspectivas mostraram-se freqüentemente divergentes. Os episódios apresentados nesse trabalho permitem uma análise dessa diversidade de perspectivas, propiciando interpretações e ações que por vezes ocasionam desencontros ou interrupções nas interpretações e no fluxo de interações.
\end{abstract}

Palavras-chave: Perspectiva do pesquisador, Perspectivas divergente, Bebês na creche, Episódios de interação.

\begin{abstract}
Multiple perspectives about young infants playing at day care. This work emerged as a secondary focus in an initial research about child-child interaction. It proposes a look at the research process analyzing the "collecting the data" itself, bearing in mind that the data are not given, but constructed in the interaction between the researcher's network of meanings and the events observed in the here-and-now situation. Therefore, from the premise of human structural limitation to the access of an independent external reality (Maturana \& Varela), this second focus of research proposes three different perspectives about the "collected data" to be equally considered: 1) the researcher's perspective; 2) the perspective of the caregiver responsible for the children; 3 ) the children's themselves. These perspectives are often divergent from each other. The analysis of some episodes shows that some interpretations and actions may lead to mis-encounters or interruptions in the interpretations and flow of actions.
\end{abstract}

Key words: Researcher's perspective, Divergent perspectives, Babies at day care, Interactive episodes.

$\mathrm{O}$ presente estudo surgiu como um foco derivado de uma pesquisa inicial sobre interações criança-criança nos primeiros dois anos de vida, realizada em uma creche universitária (Franchi-e-Vasconcelos \& RossettiFerreira, no prelo). Nesse estudo tínhamos por objetivo específico analisar, através do registro em vídeo e análise microgenética, episódios de encontros entre crianças já que a literatura mostra-se bastante contraditória sobre a existência ou não de interação nesta idade.

As sessões de gravação aconteceram durante o período de março a maio de 1999, em três sessões semanais de uma hora de duração cada. O pesquisador permanecia esse tempo na creche (em cada sessão) e começava a gravar apenas quando alguma possível situação interativa tinha início. Foram sujeitos desses recortes 19 crianças (10 - 19 meses).

$\mathrm{O}$ fato de nosso estudo ter sido feito em um ambiente de educação/cuidado coletivo de crianças determinou algumas de suas características. A creche cria campos de interação criança-criança que são mais disponíveis (maior número de crianças e menor de adultos). Seleciona não intencionalmente determinados tipos de criança e suas famílias (geralmente aquelas cuja mãe trabalha e precisa compartilhar os cuidados 
dos filhos). Impõe, ainda, possibilidades e limites às próprias brincadeiras, a depender de como são organizados o ambiente e as atividades da creche.

Mais especificamente, nosso estudo foi feito em uma creche universitária que conta com um tipo de clientela formada por filhos de professores, estudantes e funcionários da universidade. Além disso, a direção da creche possui uma proposta de cuidado e educação das crianças que parte da noção de que mesmo o bebê é um ser ativo. A proposta pedagógica deve possibilitar-lhe, então, seu desenvolvimento em direção a ser uma pessoa autônoma e criativa. Este estudo foi feito dentro deste contexto e os tipos de episódios que dele emergiram, apesar de não serem passíveis de generalização para qualquer outra situação de creche, servem como importantes sinalizadores de como se dão os processos interativos.

Dessa forma, observar crianças brincando na creche tornou-se uma experiência rica em possibilidades de interpretações quando, apesar de mantermos nosso foco de interesse nas crianças, ampliamos nosso recorte inicial e incluímos outros sujeitos e elementos do contexto imediato presentes na cena. Além disso, no cotidiano das relações na creche, de maneira intencional ou não, os adultos que estão em contato com essas crianças pequenas, tanto podem promover como interromper suas interações. Nas interações adulto-criança, o papel do parceiro mais experiente é bastante norteado pelas concepções vigentes no grupo cultural ao qual este adulto pertence e formam uma rede de significações que significa e é significada pelas pessoas que dela fazem parte.

\section{A Rede de Significações}

A perspectiva da Rede de Significações, em elaboração pelos pesquisadores do CINDEDI (Rossetti-Ferreira, Amorim \& Vitoria, 1996; Rossetti-Ferreira, Amorim \& Silva, 2000), é uma perspectiva teórico-metodológica que tem como meta a construção de um instrumento que contribua com a organização de dados e com a análise dos processos de desenvolvimento humano. Segundo esta perspectiva, o desenvolvimento humano se dá através de um processo sócio-histórico de significações. Para os pesquisadores que adotam a perspectiva sócio-histórica, o psiquismo da pessoa é construído nas e através das dialéticas interações com os outros parceiros de interação, em situações específicas, dentro de contextos sociais mais amplos, através das quais os signos sócio-culturais vão sendo gradativamente apropriados num contínuo processo de constituição da pessoa (Vygotsky, 1984; Wallon, 1986). Valsiner (1987) afirma que existe uma relação de interdependência entre os constituintes do sistema pessoameio, de maneira que a pessoa não pode funcionar sem o ambiente e o meio (da pessoa) não seria o mesmo se a pessoa fosse eliminada dele. Mais do que isso, a presença de outro indivíduo (ou indivíduos) no processo de transação indivíduo-ambiente faz com que uma ação individual, que surgiu na transação pessoa-ambiente, não seja um evento solitário, mas social, pela simples presença do outro. O desenvolvimento humano é, portanto, uma construção compartilhada, na qual tanto a criança quanto seus parceiros se co-constroem nas interações que estabelecem e o ambiente é então con- cebido tanto como espaço social de experiência, como enquanto condição/instrumento de desenvolvimento (Oliveira \& Rossetti-Ferreira, 1993).

Segundo Rossetti-Ferreira e colaboradores (1996), um conjunto de fatores físicos, sociais, ideológicos e simbólicos influenciam, a cada instante, todo fazer humano e este conjunto deve ser interpretado como uma rede de significações:

Essa rede constitui um meio, o qual a cada momento e em cada situação captura/recorta o fluxo de comportamentos do sujeito, tornando-os significativos naquele contexto. Por outro lado, cada sujeito, ao agir, está também recortando e interpretando de forma pessoal o contexto, o fluxo de eventos e os comportamentos de seus interlocutores, a partir de sua própria rede de significações (Rossetti-Ferreira et al., 1996, p. 138). Esta rede/malha de significações está inscrita no sujeito, construída que é através de suas experiências anteriores, podendo estar inscrita no corpo, no gesto, na forma de sentir e agir (Rossetti-Ferreira et al., 1996, p.142).

Assim, as relações sociais são continuamente coconstruídas a partir de interações, de ações partilhadas e interdependentes que são estabelecidas entre as pessoas (Rossetti-Ferreira, Amorim \& Silva, 1999). Estas interações são articuladas através de coordenação de papéis e contrapapéis que são assumidos, negados e/ou recriados pelos participantes (Oliveira, 1988, 1994; Oliveira \& Rossetti-Ferreira, 1993, 1994).

Nesse presente trabalho, o processo de se fazer pesquisa (o observado entrelaçado à nossa base teórica) revelou a possibilidade de existência de múltiplos pontos de vistas como, por exemplo, o ponto de vista do pesquisador, de cada uma das educadoras e o das próprias crianças. O suporte teórico dado pelos trabalhos de Maturana e Varela mostrounos que, mais do que a existência de múltiplos pontos de vista, estes são igualmente válidos, já que é impossível para cada um dos envolvidos na construção destes pontos de vista ter um acesso privilegiado a uma realidade objetiva que exista independente de nós.

\section{A Biologia do Conhecimento}

Segundo Maturana e Varela (1995, 1997), os sistemas vivos são sistemas que podem ser distinguidos por um observador como sistemas compostos, ou seja, formado por partes. A essa viabilização de um sistema vivo através da dinâmica de seus componentes e das relações (e relações de relações) entre seus componentes, os autores chamaram de estrutura do sistema. Para eles, somos seres vivos "determinados estruturalmente". Ou seja, o que pode acontecer a um sistema vivo é determinado pela sua estrutura. E, por sua vez, a estrutura desse sistema é, no seu presente estrutural, fruto da história de interações desse sistema consigo mesmo (através de mudanças nas relações entre as partes deste sistema), com seu meio e com outros sistemas vivos. Apesar disso, todas estas interações são consideradas apenas como perturbações para esse sistema, já que quem determina se uma perturbação do meio é uma interação do sistema vivo com este meio é a estrutura desse sistema. A isso, Maturana e Varela chamaram de determinismo estrutural: 
Dado que a estrutura de uma unidade composta está determinada em qualquer momento por seus componentes e suas relações, qualquer mudança na estrutura de uma unidade composta só pode surgir determinada por sua estrutura pela operação das propriedades de seus componentes, suas interações como unidade composta só podem desencadear nela mudanças estruturais determinadas em sua estrutura sem especificá-las. (...) a estrutura de uma unidade composta determina as configurações do meio com as quais ela pode interagir. As unidades compostas, consequentemente, são sistemas determinados estruturalmente. (...) Depois dessas considerações é evidente que, se os sistemas vivos são sistemas determinados por sua estrutura, o fenômeno da percepção como um fenômeno de captação de traços de entes independentes não pode ocorrer, porque não existe um mecanismo através do qual tais entes possam determinar o que acontece num sistema sensorial em uma interação. O meio pode somente desengatilhar, pode apenas desencadear uma mudança estrutural determinada na estrutura do sistema sensorial do organismo. (Maturana, 1997b, p. 84 e 85$)$.

Partindo destes conceitos, Maturana nos diz que em todo estudo sobre o fenômeno de conhecer, de como chegamos a conhecer alguma coisa, temos dois caminhos para explicar este fenômeno. No primeiro deles, que o autor chama de $\mathrm{Ob}$ jetividade-sem-parênteses, não levamos em conta as características do Conhecedor, daquele que conhece, a quem Maturana chama de Observador. Neste caso, a cognição surge como uma característica intrínseca do observador. $\mathrm{O}$ observador conhece o mundo através da percepção de características deste mundo captadas pelo seus órgãos sensoriais. Por este caminho, vivemos em um mundo que nos é prédado, que existe, da maneira que o conhecemos, independente de nós.

Pelo outro caminho, ao qual Maturana chama de Objetividade-entre-parênteses, em todo fenômeno de conhecer levamos em consideração as características daquele que conhece. O fenômeno de cognição passa a ser, então, algo dependente das características do sistema vivo que conhece (do observador), da estrutura desse sistema. Assim, deixa de existir o conceito de uma percepção que esse sistema cognitivo possa ter do mundo, porque o mundo que o observador traz à baila é fruto de suas distinções sobre esse mundo. E as suas distinções, suas interações com o seu meio, são determinadas pela sua estrutura presente (pelo estado de sua estrutura no momento que tal interação ocorreu, estado esse, por sua vez, que é o produto do processo histórico de suas interações prévias). Todo fenômeno perceptivo, por esse caminho explicativo, depende da estrutura daquele que percebe. Dessa forma, torna-se impossível validar qualquer afirmação cognitiva da existência de um mundo objetivo que exista sem a nossa participação nesse mundo. Maturana \& Varela (1995) não negam a existência de um mundo objetivo, apenas afirmam que nos é impossível acessá-lo, pois sempre que o fazemos, isso acontece através de nossa estrutura. Assim, o conceito de um mundo único, pré-dado e objetivo, deixa de existir e é substituído pelo conceito da existência de tantos mundos possíveis quantas possibilidades de distinções o observador possa fazer. O conceito de uma realidade objetiva única é substituído pelo conceito de múltiplas verdades. Apesar disso, essas afirmações não propõem um relativismo total em que tudo passa a ser possível. Nós, seres humanos, construímos mundos que são semelhantes, pois compartilhamos uma estrutura fruto de uma mesma história evolutiva (nossa filogênese) e, no âmbito individual (em nossa ontogênese), é o resultado de toda história de interações particulares do organismo. Portanto, também produz variações e diferenças na construção desse(s) mundo(s) que partilhamos. Assim, produzimos conhecimentos possíveis de serem partilhados pois vivemos mundos semelhantes.

A partir do conceito de uma objetividade-entre-parênteses, nossos resultados puderam ser repensados. A impossibilidade de validar esses resultados em uma realidade externa independente abriu o fazer científico não só à possibilidade de existência de múltiplos domínios de realidades, mas também ao respeito a estes diferentes domínios ${ }^{1}$.

Dessa forma, uma mesma cena recortada pode propiciar diferentes leituras que são feitas a partir do ponto de vista dos sujeitos envolvidos no episódio. No episódio transcrito a seguir vamos exemplificar essa possibilidade de pontos de vista divergentes. Gostaríamos de ressaltar que os outros pontos de vista comentados neste exemplo também fazem parte de uma "visão do pesquisador" sobre eles e que, por isso, são exercícios de interpretação e que não necessariamente espelham o conteúdo intrapsíquico dos outros envolvidos no episódio:

\section{Episódio 1 (O Ponto de Vista do Pesquisador)}

\section{"Não fui eu quem fiz ela chorar"}

Aline $^{2}(18 \mathrm{~m})$ está ajoelhada no degrau de um caixote de madeira em formato de escada. Vando (16m e 15d) e Gia (20m) se aproximam de Aline. Gia também se ajoelha no mesmo degrau. Gia aproxima-se do rosto de Aline, encostando a boca como se a beijasse e, ao mesmo tempo, vai empurrando-a devagar. Aline começa a chorar, dizendo: “Ai, ai, ai!”. Uma funcionária da creche, que não lida diretamente com as crianças, mas que estava passando, olha para Aline e Gia. A Funcionária se aproxima, pega Aline e a coloca mais para o lado do degrau, dizendo: "Vem mais um pouco para cá ..." Aline pára de chorar e a funcionária vai embora. Vando passa a mão no cabelo de Aline. Gia, ainda dividindo o mesmo degrau com Aline, empurra-a novamente e esta volta a chorar, quase gritando. Vando tenta subir no degrau em que estão as duas meninas. Aline chora gritando. Gia continua empurrando-a devagar.

Educadora Fernanda (responsável pelas crianças) diz, de longe: "Vando!!!" em tom enérgico. Vando pára de tentar subir e olha para educadora. Gia também pára de empurrar e olha para educadora. Aline debruça-se, encostando a cabeça no degrau e continua a chorar forte. Gia vira a cabeça e olha para ela de novo. Educadora vem e tira Vando do degrau, levando-o para outro lugar. Aline continua a chorar. A educadora Fernanda volta, coloca a mão nas costas de Aline dizen- 
do: "Pronto, ele já saiu!" Gia olha para Aline que continua a chorar. Educadora pega Aline no colo enquanto diz: "Vem!" Gia sai do degrau, ficando em pé ao lado da escada, olhando para a direção da educadora e sorrindo. Gia sobe novamente no degrau.

\section{Episódio 1 (Visão do pesquisador sobre a perspectiva} das crianças):

Este é um exercício imaginário e de caráter apenas ilustrativo feito a partir do ponto de vista do pesquisador, como uma suposição sobre possibilidades de sentimentos e ações das crianças).

\section{Episódio 1 (Visão do pesquisador sobre a perspectiva} das educadoras):

Também um exercício imaginário, a partir do ponto de vista do pesquisador, porém baseado em conversas com as educadoras e observações posteriores ao recorte deste episódio, que forneceram pistas mais concretas sobre as significações e ações das educadoras)

Este episódio nos fornece pistas bastante delineadas das múltiplas visões possíveis de uma mesma situação interativa. Pelo ponto de vista do pesquisador, vemos que, além do adulto interferir, ele o faz a partir de premissas que possui e que não necessariamente são condizentes com a situação. Aline, baseada em outras situações observadas por nós e em conversas com a sua educadora, chora "exageradamente" em situações em que é contrariada. Essa reação, por ser exacerbada, freqüentemente atrai a atenção dos adultos que estão por perto. Neste episódio, uma funcionária da creche que não lida diretamente com o cuidado dessas crianças foi a primeira a interferir e a tentar "dividir" o espaço da escada entre as crianças. Na segunda interferência, feita pela educadora Fernanda, ela retira Vando da escada, provavelmente baseada em conceitos prévios que ela possui a respeito dele, como se ele estivesse fazendo algo que estivesse "perturbando" Aline (do ponto de vista da educadora). Essa retirada de Vando da escada é baseada em significações anteriores da educadora. Ele é significado pela educadora como uma criança agressiva, a partir da história particular de interações que aconteceram entre eles, na creche. Por outro lado, o pesquisador e sua rede de significações, durante o período em que esteve gravando na creche, não significou a criança da mesma maneira. Isto possibilitou, inclusive, a compreensão diferenciada do episódio citado acima, em que Vando é retirado do local "por fazer uma coisa que não estava fazendo".

Através do nosso exercício imaginário de pontos de vistas (o das crianças e o das educadoras) sugerimos, baseados em nossa observação e conversas com os adultos envolvidos no processo de cuidado das crianças, outras possibilidades de significação da mesma situação recortada por nós.

Quando o significado que emerge de um episódio de interação é semelhante e partilhado pelos vários participantes do episódio, a pluralidade de possibilidades de pontos de vista pode ser mascarada. Porém, nas situações (como no episódio anterior) em que vemos os conflitos de significações, os múltiplos pontos de vista são realçados. Quando vemos que não vemos a mesma coisa que o outro, vemos o outro. Nessas situações, num jogo de figura e fundo, se temos como figura um aparente compartilhamento dos mesmos significados, como fundo há uma série de possibilidades diferentes, inclusive de desacordos, que só uma situação de conflito faz com que venham à tona.

$\mathrm{O}$ ponto de vista do pesquisador, a partir desta perspectiva, é apenas mais um dos possíveis pontos de vista. O pesquisador, apesar de sua posição de "espectador", também é guiado por suas expectativas sócio-culturais e suas concepções sobre ciência. O episódio que descreveremos a seguir mostra esta situação de maneira bastante clara.

\section{Episódio 2 \\ "Não é assim que é a brincadeira!!!"}

Lica $(17 \mathrm{~m})$ e Mila (11m) estão no pátio interno da creche, juntas. Lica está no interior de um banco retangular que está colocado invertido no chão, delimitando um espaço, uma área circunscrita. Lica está agachada mexendo em alguns bloquinhos de plástico e Mila está olhando para ela. Lica estende as duas mãos "oferecendo" os bloquinhos para Mila que olha para os bloquinhos e pega um dos bloquinhos da mão de Lica. Lica estende a mão novamente com outro bloquinho. Mila pega o outro bloquinho com a outra mão. Mila, após pegar os bloquinhos, se vira de costas para Lica e sai andando. Lica se levanta, dentro do banco e vocaliza alto: “Nã! Nã!!". Mila, que estava andando e se afastando, perde o equilíbrio e cai. Lica sai de dentro do banco e vai se aproximando de Mila, olhando para ela, enquanto balança a mão com um dedo esticado como num gesto de "não". Mila se levanta e se vira na direção de Lica. Lica toca o braço de Mila, olhando para ela e depois retira a mão, "parecendo conduzila". Lica começa a caminhar em direção ao banco invertido novamente. Mila olha para Lica e vai seguindo-a em direção ao banco.Lica entra novamente no banco, as duas estão olhando uma para a outra. Lica pega um bloquinho da mão de Mila e coloca na área interna do banco invertido. Depois pega o outro bloquinho que está com Mila e também joga dentro do banco. Mila olha para os bloquinhos no interior do banco. Lica passa para dentro do banco enquanto vocaliza alguma coisa. Mila se agacha, apoiando no banco. As duas se olham. Lica se agacha no banco e pega os dois bloquinhos que tinha jogado ali anteriormente, estende as duas mãos,"oferecendo" os bloquinhos para Mila. Lica estende a mão "dando" os bloquinhos para Mila. Mila pega os bloquinhos mas deixa um deles cair. Lica sai de dentro do banco, dando a volta por fora dele, e vai até junto de Mila. Pega o bloquinho que está no chão e coloca em cima do outro que Mila está segurando. Mila olha para o bloquinho, mexe um pouco a mão e o bloquinho cai no chão novamente. Lica segura o braço de Mila e diz: "Nã!!!" olhando para seu rosto. Mila também olha para ela. Lica passa para o lado de dentro do banco. As duas crianças voltam a ficar em posição semelhante a que estavam no começo do episódio: Mila está sen- 


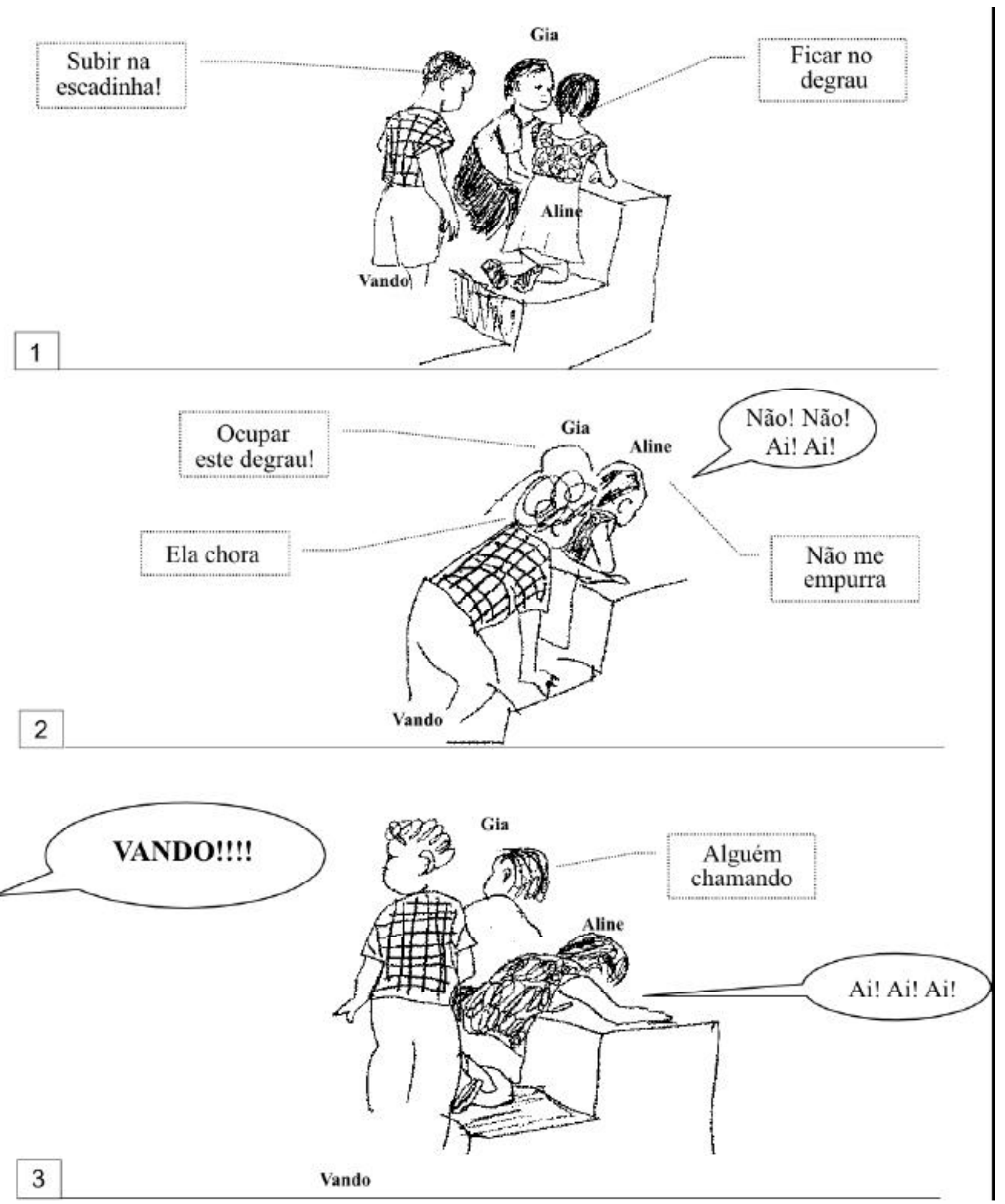

Figura 1

Visão do pesquisador sobre a perspectiva das crianças. 

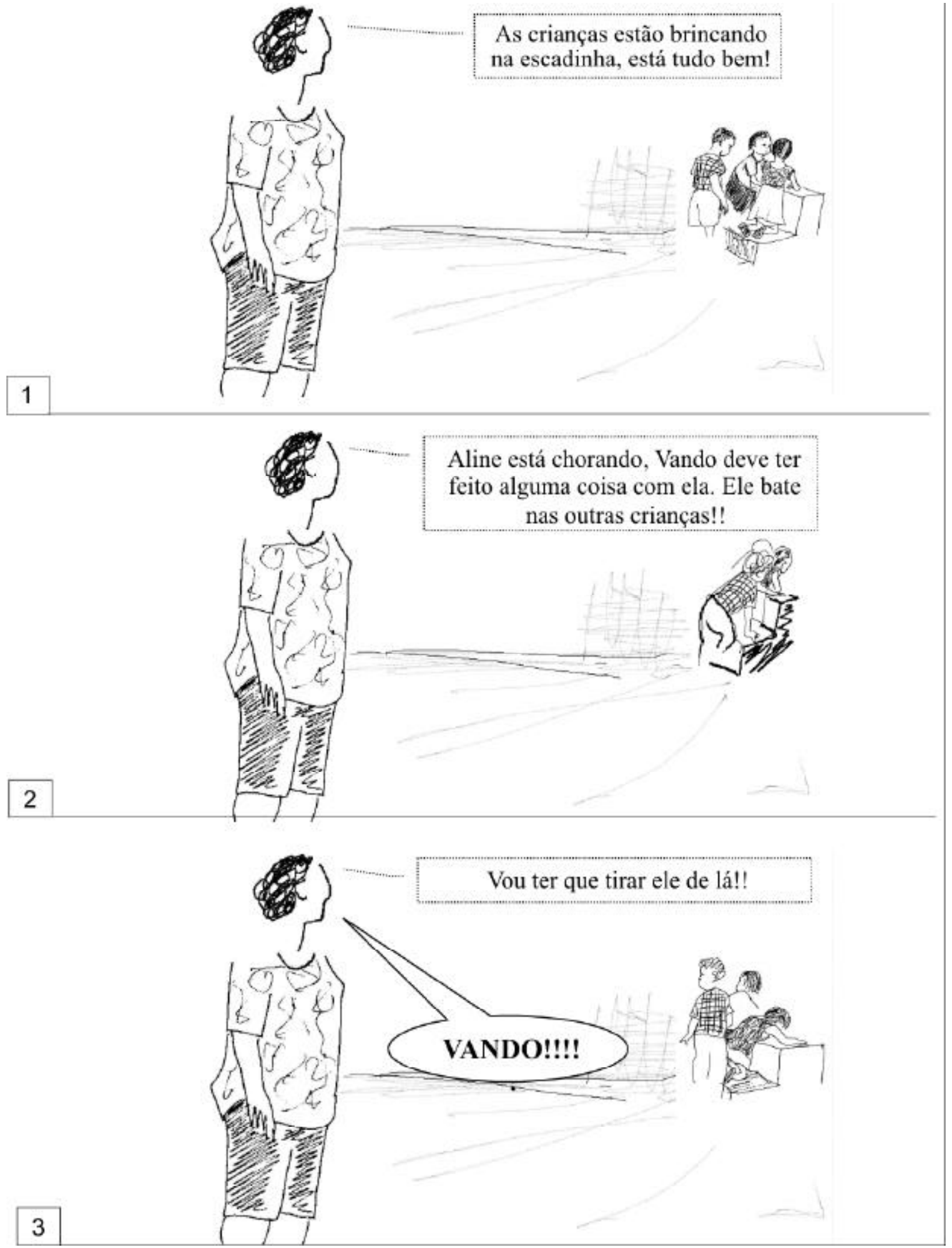

Figura 2

Visão do pesquisador sobre a perspectiva das educadoras. 
tada do lado de fora do banco e Lica está agachada do lado de dentro. Lica pega um dos bloquinhos que está com Mila e o coloca dentro do banco. Educadora Nívea diz para uma outra criança:'Vamos lá com a Mila?" e Mila olha na direção da educadora. Lica pega o bloquinho que tinha colocado dentro do banco, estende a mão na direção de Mila, por cima da madeira do banco e o bloquinho cai de sua mão. As duas olham para a educadora Nívea que está chegando com outra criança.

Quando Lica se levanta dizendo "nã, nã" e vai atrás de Mila (que estava se afastando com os bloquinhos), a situação sugere, aos olhos do pesquisador, uma possível "disputa" ou tentativa de retomada dos objetos que estão com Mila, pela outra criança. Mas os acontecimentos que se sucedem mostram que Lica está mais "interessada" numa possível brincadeira que esteja acontecendo entre elas (as crianças), do que simplesmente na recuperação dos brinquedos em si. Os objetos, nessa situação interativa, possuem um claro papel de mediadores do encontro das crianças.

Assim, fica claro como as expectativas do pesquisador em relação ao próprio desenrolar da situação não são necessariamente confirmadas pelos acontecimentos. No começo, as duas crianças estão juntas (cada uma de um lado do banco), Lica dá os bloquinhos para Mila que, por sua vez, sai andando e se afastando do local. Para o pesquisador, o conceito de que crianças nesta faixa de idade interagem bastante com os objetos faz parte de sua rede de significações e foi construído a partir de seus estudos da literatura sobre o tema (Becker, 1977; Vandell \& Mueller, 1980; Vandell, Wilson \& Buchanan, 1980; Smith \& Connolly, 1980; Stambak \& Verba, 1986; Schaffer, 1996) e também baseado em suas observações anteriores das interações criança-criança nas fitas de vídeo previamente gravadas nessa mesma creche. No episódio acima descrito, todos esses conceitos guiaram nosso recorte.

Nossas expectativas, nesse sentido, durante o fazer científico, têm que ser encaradas como guias, como linhas que direcionam nosso olhar que, por sua vez, foi sendo construído na práxis das situações juntamente com as explicações que elaboramos a priori e a posteriori do viver destas situações. Neste sentido, uma frase de Humberto Maturana (1997c), dita informalmente durante uma palestra, torna-se exemplar: "Não é maravilhoso como nem sempre nossas expectativas são correspondidas!" Esta frase nos diz que, apesar das expectativas de pesquisadores guiarem nosso olhar, o fato delas nem sempre serem correspondidas sugere que nossa interferência, nosso viés sobre o observado possui um certo controle, permitindo que o conhecimento que estamos construindo possa ser passível de ser replicado por outros observadores da mesma comunidade de observadores a que pertencemos. Mantendo um rigor em nossas observações e análises, sempre atentos às nossas próprias interferências, obteremos um corpus de dados bastante rico em possibilidades de interpretações, sempre tendo em nosso fazer ciência a máxima de que "os dados são construídos, mas não são inventados.” (Goldenberg, 1997).

Esses embates, essas diferenças entre nossas expectativas sobre os dados e os próprios dados são, portanto, sinalizadores importantes sobre o processo de construção desses dados quando usamos, como referência, perspectivas teórico-metodológicas abrangentes como a da Rede de Significações.

Por isso, a experiência em pesquisa exige, num primeiro momento, uma vivência do pesquisador na/com a situação pesquisada, um mergulho do pesquisador como observador participante. Este adentrar na situação permitirá ao pesquisador uma visão mais ampla e um primeiro delineamento da rede de significações que pretende estudar (Rossetti-Ferreira, Amorim \& Silva, 1999).

Neste processo de observar o observar do pesquisador, os embates entre nossas expectativas sobre os acontecimentos e o observado se revelam como uma capacidade de enxergar esboços das diferentes redes de significações (o recorte e a interpretação pessoal do contexto, do fluxo de eventos e dos comportamentos, canalizados por aspectos individuais, formam a rede de significações particular da pessoa) dos envolvidos no episódio analisado que, por sua vez, irá nos fornecer pistas sobre a rede de significações enquanto perspectiva teórico-metodológica.

Acreditamos que em pesquisa não há como escapar de nosso próprio ponto de vista. É ele que nos dá a possibilidade de interpretar o que observamos, ele é o único caminho. Portanto, essa questão envolve uma ambigüidade inerente. Por um lado, um cuidado deve ser tomado para não interpretar de modo pessoal as situações em investigação. No entanto, essa interpretação só vai ser possível através desse mesmo aspecto, em um processo em que signos culturalmente definidos são compartilhados. O papel do pesquisador é então o de co-construtor desta realidade. O recorte e a análise de determinado episódio se configuram juntos à distinção desse mesmo episódio. Para Carvalho, Império-Hamburger \& Pedrosa (1999) são as formas de pensamento que articulam as opções metodológicas diante de determinada situação de construção de conhecimento. É através da articulação entre os procedimentos e as perguntas perseguidas, numa imbricação entre os referenciais teóricos e o observado, que o observado adquire o status de "dado":

O observado é o ponto de partida comum a qualquer teorização, em qualquer área ou disciplina científica. Ao mesmo tempo, o observado é necessariamente recortado e constituído como dado a partir de um referencial de pensamento, que ele por sua vez retroalimenta e transforma. (...) O método é pensamento sistemático, moldado por um quadro teórico, e organizador da experiência com o objetivo de construir conhecimento compartilhável sobre o fenômeno-alvo. (Idem, p. 2).

O episódio apresentado a seguir ilustra esta imbricação entre o observado e os referenciais teóricos do pesquisador e sua consequiente distinção e análise da situação.

\section{Episódio 3:}

\section{"Olha a sua boca!"}

Lica (16m) e Mila (10m) estão sentadas no chão, uma de frente para a outra, no pátio interno da creche. Mãe chega 
com Lú (15m) no colo, agacha-se e coloca a filha perto de Lica e Mila. Lú fica em pé, perto das duas crianças. Lú coloca a mão na boca de Lica e depois coloca a mão na boca de Mila. Lica está olhando para Mila que está olhando para a mão/ rosto de Lú. Mila está com a boca um pouco aberta como se estivesse "recebendo algo para comer". Lú vai andando até sua mãe e as duas crianças sentadas a acompanham com o olhar. Mila coloca sua mão direita na própria boca (olhando para Lú). Lica e Mila estão olhando para a Lú e sua mãe. Mãe se levanta, com Lú no colo, e vai para outro lugar. Lica se inclina para frente e estende a mão, com um dedo esticado, quase encostando na boca de Mila. Depois recua o braço. Volta a estendê-lo novamente quase tocando de novo a boca de Mila, enquanto olha para uma educadora que passa (andando na sua frente) e volta a olhar para Mila. Mila fica com a boca um pouco aberta, olhando para o dedo/rosto de Lica. Lica quase encosta o dedo na boca de Mila.

Neste episódio, quando a educadora passa perto das crianças, Lica já quase encostou o dedo na boca de Mila e recuou o braço. Volta a esticá-lo e a quase encostar na boca de Mila, enquanto olha para a educadora. Neste momento, o gesto de encostar a mão na boca de Mila "parece se transformar" em um gesto de apontar para a boca da criança. Sob o ponto de vista do observador (o pesquisador), quando a educadora que está passando é inserida no contexto, muda-se o referencial. Amplia-se o foco de distinção e o gesto de tocar a boca da outra criança é distinguido pelo observador agora em função também da educadora e, com isto, transforma-se num gesto de apontar. O foco de interpretação do pesquisa- dor se amplia, mas ainda sempre continua contendo o outro e seu gesto que, eventualmente pode ser também o gesto de apontar.

Inicialmente na nossa pesquisa, percebíamos o papel dos adultos/educadoras como o de interferir nas interações criança-criança, freqüentemente interrompendo-as. $\mathrm{O}$ viés do pesquisador começou a ser evidenciado a partir de dois caminhos. O primeiro deles foi o próprio "coletar dos dados", a praxis da pesquisa. Nela, o fato de se recortar determinado episódio e, como dito anteriormente, ao mesmo tempo estar imerso no restante da situação (nos gestos, olhares e falas dos adultos e crianças, educadoras não necessariamente participantes da cena que estava sendo gravada, mas que estavam no ambiente) proporcionou uma "sensação" de vários outros acontecimentos inter-relacionados que "escapavam" do registro das gravações. Concomitante a esta experiência vivida configurou-se o segundo caminho: o da explicação dessa experiência, a partir da leitura da obra de Maturana e de seu conceito de múltiplas verdades. Dessa forma, o viés inicial do pesquisador que poderia direcionar os recortes de dados foi sendo substituído, através dos caminhos acima descritos, por uma noção de múltiplas perspectivas.

$\mathrm{Na}$ Figura 3, esquematizamos os principais recortes feitos pelo pesquisador durante o processo de construção dos dados.

Vemos então que os encontros entre as crianças (representado pelos círculos e pelas setas cheias nas duas direções) podem sofrer interferências das educadoras tanto promovendo (1) como interrompendo (2) estas interações. Essas

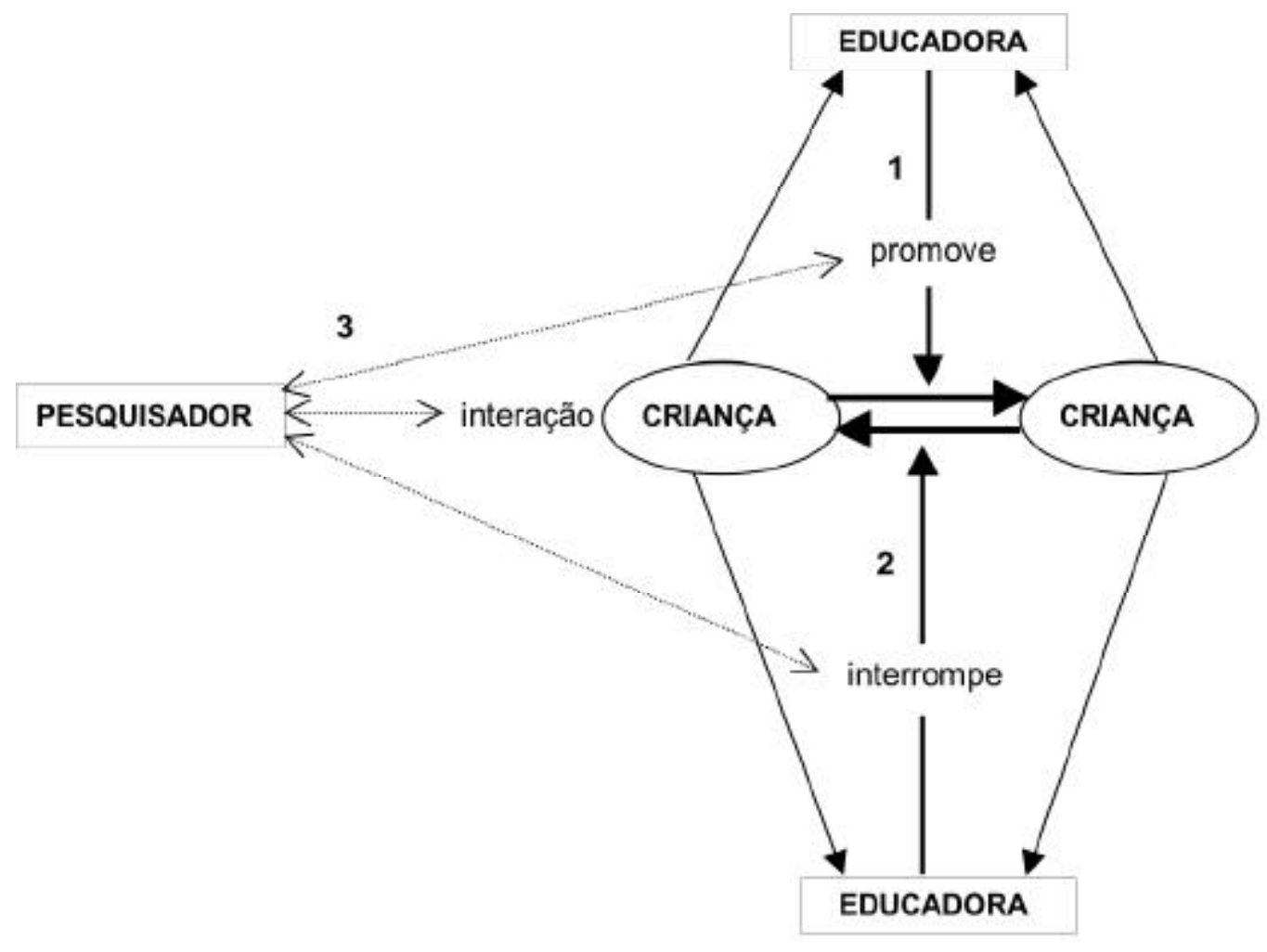

Figura 3. Diferentes distinções do pesquisador diante da situação observada. 
ações das educadoras são sinalizadas também pelas ações das próprias crianças (representadas no diagrama pelas linhas cheias com as setas em direção à educadora) e, dependendo do significado atribuído por elas àquela ação (ou conjunto de ações), atuam sobre a situação.

Por sua vez, o pesquisador também distingue algumas das ações, gestos, olhares e vocalizações das crianças como interações ocorridas entre elas (3). O mesmo acontece em relação às ações das educadoras e, conforme estas ações, o pesquisador as distingue como capazes de promover ou interromper as interações das crianças. Na figura, as setas nas duas direções representam o recorte feito pelo pesquisador a partir das sinalizações dadas pelas crianças e pelas educadoras. A linha pontilhada representa a possibilidade de diferença entre o ponto de vista do observador e o dos outros participantes do episódio. Pelo esquema, vemos que o recorte do pesquisador distingue tanto os episódios de interações, quanto as possíveis interferências que possam ocorrer. Semelhante à teoria de Maturana sobre a impossibilidade estrutural de acesso a uma realidade objetiva única e independente de nós, o acesso do pesquisador à situação estudada também é feito através de seu ponto de vista (sua base teórica imbricada ao observado, sua rede particular de significações). Assim, em relação aos outros pontos de vista, é importante lembrar que sempre estamos falando da visão do pesquisador sobre eles, o que não nos impede de afirmar sua existência e de fazer algumas interpretações. Dessa maneira, destacamos os seguintes pontos de vista que estiveram bastante presentes em nossa pesquisa:

\section{1) Ponto de vista do pesquisador}

A partir de dados da literatura sobre interação criançacriança, sabemos que as crianças mais velhas têm uma forma mais elaborada de interação que as mais novas, onde ações recíprocas e coordenadas entre os parceiros (Eckermann \& Didow, 1988; Império-Hamburguer, Pedrosa \& Carvalho 1996, Carvalho et al., 1999), jogos de papéis e contra-papéis (Oliveira, 1988) são bastante evidentes.

Nós, enquanto pesquisadores, fazemos nossas distinções de acordo com nossas expectativas. Nossas distinções incluem a observação das crianças interagindo entre si. As interferências dos adultos (particularmente das educadoras) agem sobre a distinção de nossas distinções de interações. Por este ponto de vista, as interações criança-criança estão em processo inicial de construção e essas interações parecem acontecer mais no aqui e agora das situações, sendo fragmentadas e ao mesmo tempo estruturadas (com o repertório de significados que elas possuem) na medida do possível daquele momento. Porém, esse repertório, assim como a coordenação de comportamentos entre as crianças, nestas interações, são mais simples se, e somente se, as compararmos com as interações de crianças mais velhas.

Desta maneira, certos conceitos e expectativas estão localizados na figura do observador (no nosso caso, do pesquisador) e não no sistema estudado. Comparamos interações de crianças bem pequenas com interações de crianças mais velhas e dizemos que as primeiras são bastante caóticas e pouco coordenadas. Porém, quem tem acesso à observação dessas crianças pequenas interagindo e também tem acesso às crianças mais velhas e pode compará-las, é o observador. A explicação do fenômeno, pelo observador, é sempre uma reformulação do fenômeno, feita através da experiência e da linguagem.

No momento do episódio 3, em que Lica estende a mão até a boca de Mila enquanto olha para a educadora que passa por ela, podemos dizer que o gesto de colocar a mão na boca da outra criança se transforma em um gesto de apontar para a boca de Mila. Por que essa leitura do gesto é possível? Porque ampliamos nosso recorte do episódio e um gesto feito entre as duas crianças passa a incluir uma terceira pessoa como referencial. Mas podemos ter certeza de que esse gesto de tocar a boca realmente se transformou em um gesto de apontar "dentro" do episódio recortado? Ou o gesto foi percebido pelo observador?, pela rede de significações do pesquisador, por conceitos externos ao sistema interativo observado?

O conceito de observador em Maturana (1997a, b) e Maturana e Varela $(1995,1997)$ traz à tona uma discussão importante sobre expectativas, qualificações, classificações que estão no observador e não no sistema observado.

2) (uma visão do pesquisador sobre o) Ponto de vista das educadoras

Uma suposição a se fazer é que as educadoras (e os adultos em geral) acham que crianças interagem mais com brinquedos e com adultos do que com parceiros de idade, ou que quando interagem com as outras crianças, a disputa de brinquedos é seu único foco de interesse.

Algumas falas de educadoras ilustram este ponto de vista. Estes dados foram recortados de entrevistas feitas com outras educadoras (Vitória, 1997) durante processo de adaptação de um grupo de bebês (7-14 meses) à mesma creche estudada por nós, no ano de 1994:

\section{Educadora Maria:}

(pergunta: Como é que acontece a interação entre as crianças da sua turma?)

- Geralmente, assim quando eles estão brincando, com brinquedo, um vai pega, daí eles brigam, daí já se entendem, eu acho que isso já é uma interação entre eles.

(...) Então eu acho que é um motivo dela tá reagindo desse jeito também, é por isso pela disputa que ela tem de ter diariamente lá na creche. Que em casa, você sabe filho único, não tem o que disputar, pelo contrário não tem disputa nenhuma e é muito difícil pra criança, pro adulto já é muito difícil imagina pra criança, né?

\section{Educadora Ana} va?)

(pergunta: E interação com outras crianças, você obser-

- Ele sim, ele tem, só que assim, ele... se ele pega um brinquedo, ele fica ali no meio... mas ele não é do tipo que tira 
da outra. Ele fica ali com o dele, numa boa, ele procura outras coisas.

\section{Educadora Teresa}

(pergunta: Mas voltando ao Moa, como é que é a interação, você observa ele interagir com outras crianças, ou não?)

- Com outra? Assim, às vezes de tomar brinquedo, eu percebo. (...) Percebo que ele é normal. Briga por causa dos brinquedos, quer o brinquedo do outro, assim, mais... fica numa boa.

\section{Educadora Sara}

(...) Aí as duas começaram a se... se entrosar, né? Uma com a outra, e uma vai, puxa a outra, outra vai, pega o brinquedo da outra, ficou assim uma coisa... gostosa, de ver assim as crianças, se comunicando uma com a outra, né? E... mas, assim sem agressividade... e... fazendo amizade, mesmo, né? (...) É bonito, sim, é muito bonito vê como que eles gosta de criança, criança gosta de criança, né? Ah, eu acho que é muito bonito sim.

(...) ele praticamente tá quase andando já, ele se levanta, já tá se levantando sozinho, pra comer sabe, come bem, dorme, enfrenta os grandão lá que, não tem medo assim, compete, disputa né?

As educadoras organizam as brincadeiras e os espaços a partir dessas distinções. E essas distinções são feitas a partir de suas redes de significações. Além disso, na creche estudada a direção pode organizar o ambiente de determinada forma, mas as educadoras que lidam com as crianças os reorganizam de acordo com suas concepções, conflitantes ou não, com as da direção. Naquele próprio meio, mesmo entre as educadoras e entre elas e outros membros profissionais dessa creche, há diferentes formas de se pensar a criança, suas capacidades e suas ações. Existem alguns significados compartilhados mais comumente, prevalentes em nossa cultura, como por exemplo, a disputa por objetos entre as crianças. Porém, significações pessoais podem atribuir uma qualidade diferente a essa disputa por objetos, que certamente não está na situação observada (a educadora Maria compara a "disputa de brinquedos" ao ato de disputar trazido do "mundo dos adultos", já a educadora Sara parece perceber esse mesmo tipo de "disputa" como algo não tão sofrido e mais prazeroso). O ato de disputar do "mundo dos adultos" é repleto de possibilidades de significados sócio-históricos, políticos, econômicos, culturais e emocionais. Quando dizemos que as crianças dessa idade competem entre si, com certeza não estamos falando do mesmo fenômeno de competição observado nos adultos. Porém, ao reformularmos a experiência interativa das crianças na linguagem, enquanto observadores, podemos lhe atribuir essa "qualidade".

Por isso, os adultos quando se propõem a interagir com crianças bem pequenas, por um lado são, claramente, promotores de desenvolvimento. Nesse processo, o sistema funcio- nal adulto-criança de participação em tarefas culturalmente estruturadas e com significados criam o que se chama de "ZDP - zona de desenvolvimento proximal" (Vygotsky, 1984, Vasconcellos \& Valsiner, 1995). Nessas situações, as instruções, apontamentos e representações dos adultos interagem com os gestos e concepções das crianças, promovendo-lhes o desenvolvimento (Oliveira, 1994; Vasconcellos \& Valsiner, 1995).

Por outro lado, porém, os adultos também são coordenados pelos valores culturais do seu grupo social, pelas suas próprias definiçõos pessoais sobre desenvolvimento infantil (sua rede particular de significações) e pelos próprios limites sensório-motores e desenvolvimentais das crianças. Entendemos que a rede particular de significações é formada pelos processos de significação da pessoa que são determinados pela história particular dessa pessoa, pelos seus limites biológicos e psicológicos. Essa rede é também a manifestação possível, na pessoa, da rede de significações, do conjunto de fatores sócio-históricos, psíquicos e emocionais que formam e são formados pela cultura em que tal pessoa vive. Conceitos como os que as crianças pequenas interagem apenas com outros adultos e com brinquedos são construídos culturalmente e vão sendo conservados e/ou alterados de acordo com o devir das situações.

\section{3) (uma visão do pesquisador sobre o) Ponto de vista das crianças}

A proximidade entre o observador/pesquisador e as educadoras, já que ambos são adultos, faz com que haja uma possibilidade maior de acerto nas interpretações do pesquisador. Torna-se mais difícil fazer suposições sobre o ponto de vista das crianças, justamente pela diferença entre as fases do desenvolvimento em que se encontram o adulto e a criança e, por conseguinte, na dificuldade de se "colocar no lugar do outro". Entre adultos, existe uma identificação maior, entre os envolvidos, na troca de papéis que é feita quando tentamos entender o outro. A forma de expressão das crianças se faz, então, através de diferentes formas, as quais nos são difíceis de captar. Não podemos supor muita coisa além do fato que o propósito da criança é criançar, ou seja, ser criança, é o de vivenciar sua experiência sensório-motora imediata de um mundo em que ela se insere gradativamente e que seu envolvimento em brincadeiras com outras crianças, por exemplo, é o envolvimento em atividades que lhe são, inclusive, prazerosas.

Concluindo, em nossas observações dos episódios de interação criança-criança, vimos como podem ser divergentes as maneiras de se ver uma mesma situação. Cada um dos envolvidos pode recortar elementos diferentes, tornando-os significativos. A partir de nossa observação e da construção dessa observação com nossos referenciais teóricos, foi possível perceber a existência de múltiplas perspectivas possíveis e delineá-las através da visão do pesquisador. Nosso próprio ponto de vista de pesquisadores é o imbricamento entre nossa vivência da situação observada, nossa base teórica e o observado. Esta justaposição forma (e é formada pela) 
nossa rede de significações que, por sua vez, significa elementos do fluxo de eventos da maneira como significamos.

Em nosso estudo, a proposição da existência de várias visões possíveis e igualmente válidas não implica numa impossibilidade de acordo com outro observador que adote a mesma perspectiva teórica-metodológica. Apenas assumimos que nossa visão é uma das explicações possíveis sobre o fenômeno e que, mesmo através do método científico, não acessamos uma realidade objetiva independente, mas sim compartilhamos um domínio de (objetividade) gerado pelas experiências semelhantes que estruturas semelhantes, em um processo histórico de viver, implicam. O que possibilita a ciência é o compartilhamento de procedimentos e de significados acordados em uma determinada comunidade científica. Assim, se um observador faz uma análise e especifica seus critérios de seleção e interpretação (uma condição necessária para o compartilhamento), um outro terá a possibilidade de "ver" a mesma coisa - ainda que discorde dos critérios e proponha outros. Nosso processo de se fazer pesquisa passa a ser, então, um processo em que percebemos e aceitamos a existência de outras perspectivas sobre o observado (por nós) e, ao mesmo tempo, continuamos a nos guiar pela nossa própria perspectiva, avançando ao assumir um foco e mantendo sempre a noção que esse é apenas um, dos vários focos possíveis. Esta abordagem traz uma relação de respeito às outras possíveis realidades distinguidas pelos outros sujeitos dessa pesquisa.

Uma outra consideração a ser feita é sobre a maneira proposta de se olhar a pesquisa científica, aqui colocada. É como se fosse um meta-olhar em que o pesquisador olha para o processo do pesquisador olhar o processo de fazer pesquisa. Como dito por Maturana e Varela (1995): "É como um olho que tenta enxergar a si mesmo". Temos que deixar claro que esse processo, em geral fragmentário, é também produto de um jogo de figura e fundo, um jogo dinâmico em que uns processos emergem e se destacam, enquanto outros se aninham num segundo plano até surgir um novo acontecimento no vir a ser das situações. Porém, apesar de todo este dinamismo, voltamos a afirmar que não estamos propondo um relativismo total das situações interativas, onde tudo passa a ser possível. Existem elementos de canalização (Valsiner, 1987) tanto nos eventos, nos comportamentos, como em nossas interpretações. Tudo é dito pelo observador, mas ele não pode dizer tudo. Existe uma canalização nas atribuições de significados que é delimitada por nossa estrutura biológica, pelo tempo histórico em que vivemos, pela nossa cultura. Assim, existem limites na interpretação, e toda discussão teóricometodológica sobre o olhar do olhar do pesquisador/observador se submete e transcende tais limites.

\section{Agradecimentos}

Os autores gostariam de agradecer à FAPESP e ao CNPq pelo suporte financeiro e às professoras Ana Almeida Carvalho e Kátia de Souza Amorim pelos valiosos comentários e sugestões feitos durante à elaboração deste artigo.

\section{Referências}

Becker, J. M. T. (1977). A learning analysis of the development of peer-oriented behaviour in nine-month-old infants. Developmental Psychology, 13, 481491.

Carvalho, A. M. A., Império-Hamburger, A., \& Pedrosa, M. I. (1999) Dados e tirados: teoria e experiência na pesquisa em psicologia. Temas em Psicologia, 7(3), 205-212.

Eckerman, C. O., \& Didow, S. M. (1988). Lessons drawn from observing young peers together. Acta Pediatrica Scandinavica, 344(77), 55-70.

Franchi e Vasconcelos, C. R., \& Rossetti Ferreira, M. C. (no prelo). A incompletude como virtude. Interação de bebês na creche. Psicologia: Reflexão e Crítica.

Goldenberg, M. (1997). A arte de pesquisar: como fazer pesquisa em Ciências Sociais. Rio de Janeiro: Record.

Império-Hamburguer, A., Pedrosa, M. I., \& Carvalho, A. M. A. (1996). Autoorganização em brincadeiras de crianças: de movimentos desordenados à realização de atratores. In M. Debrun, M. E. Q. Gonzales \& O. Pessoa Jr. (Orgs.), Auto-organização: estudos interdisciplinares (pp. 343-361). Campinas: UNICAMP.

Maturana, H. (1997a). Emoções e linguagem na Educação e na Política. Belo Horizonte: Editora UFMG.

Maturana, H. (1997b). A ontologia da realidade. Belo Horizonte: Editora UFMG.

Maturana, H. (1997c, novembro). [Conferência de abertura]. I Simpósio Internacional de Autopoiese - Biologia, Cognição, Linguagem e Sociedade, Belo Horizonte, MG.

Maturana, H., \& Varela, F. (1995). A árvore do conhecimento. São Paulo: Editora Psy II.

Maturana, H., \& Varela, F. (1997). De máquinas e seres vivos: autopoiese - a organização do vivo. Porto Alegre: Artes Médicas.

Oliveira, Z. M. R. (1988). Jogo de papéis: uma perspectiva para análise do desenvolvimento humano. Tese de doutorado não-publicada, Universidade de São Paulo, São Paulo.

Oliveira, Z. M. R. (1994). Reinações infantis: um olhar sobre as interações de crianças em creches. Dissertação de livre-docência não-publicada, Universidade de São Paulo, Ribeirão Preto, SP.

Oliveira, Z. M. R., \& Rossetti-Ferreira, M. C. (1993). O valor da interação criança-criança em creches no desenvolvimento infantil. Cadernos de Pesquisa, 87, 62-70.

Oliveira, Z. M. R., \& Rossetti-Ferreira, M. C. (1994). Coordination of roles: a theoretical - methodological perspective for studying human interactions. In N. Mercer \& C. Coll (Orgs.), Teaching, learning and interaction (Vol. 3, pp. 217-221). Madrid: Rio.

Pedrosa, M. I. P. C. (1989). Interação criança-criança: um lugar de construção do sujeito. Tese de doutorado não-publicada, Universidade de São Paulo, São Paulo.

Rossetti-Ferreira, M. C., Amorim, K., \& Vitória, T. (1996). Emergência de novos significados durante o processo de adaptação de bebês à creche. In M. I. Pedrosa (Org.). Investigação da criança em interação social. Coletâneas da ANPEPP, 1(4), 111-143.

Rossetti-Ferreira, M. C., Amorim, K. S., \& Silva, A. P. S. (2000). Uma perspectiva teórico-metodológica para análise do desenvolvimento humano e do processo de investigação. Psicologia: Reflexão e Crítica, 13, 281-293.

Schaffer, H. R. (1996). Social development. Oxford: Blackwell.

Smith, P. K., \& Connolly, K. J. (1980). The ecology of preschool behavior. London: Cambridge University Press.

Stambak, K. M., \& Verba, M. (1986). Organization of social play among todlers: an ecological approach. In E. C. Muller \& C. R. Cooper (Orgs.), Process and outcome in peer relationship (pp. 229-247). Orlando: Academic Press.

Valsiner, J. (1987). Culture and the development of children's action. New York: John Wiley \& Sons.

Vandell, D. L., \& Mueller, E. C.(1980). Peer play and friendship during the first two years. In H. C. Foot, A. J. Chapman \& J. R. Smith (Orgs.), Friendship and social relations in children (pp.181-208). London: John Wiley \& Sons. 
Vandell, D., Wilson, K. S., \& Buchanan, N. R. (1980). Peer interaction in the first year of life: an examination of its structure, content and sensitivity to toys. Child Development, 51, 481-488.

Vasconcellos, V. M. R., \& Valsiner, J. (1995). Perspectiva co-construtivista na Psicologia e na Educação. Porto Alegre: Artes Médicas.
Vitoria, T. (1997). Representações de educadoras sobre as mães e as famílias das crianças da creche. Dissertação de mestrado não-publicada, Faculdade de Medicina de Ribeirão Preto, Universidade de São Paulo, Ribeirão Preto.

Vygotsky, L. S. (1984). A formação social da mente. São Paulo: Martins Fontes. Wallon, H. (1986). Henri Wallon: Psicologia. In J. Werebe \& J. Nadel-Brulfert (Orgs.), Henri Wallon: Psicologia. São Paulo: Ática.

1 A noção do acesso a um mundo externo ser mediado pelas nossas sensações é idéia central na obra de Kant. Porém, o ponto nevrálgico da teoria de Maturana é a explicação científica da impossibilidade biológica deste acesso a um mundo externo e as conseqüentes implicações éticas desta aceitação da existência de diferentes domínios de realidades.

2 Os nomes das crianças e dos adultos foram mudados por motivos éticos.

Cleido Roberto Franchi e Vasconcelos é pós-doutorando do Depto. de Psicologia e Educação da FFCLRPUSP e bolsista FAPESP.

Endereço para correspondência: Av. Braz Olaia Acosta, 555, apto 22, Jardim Califórnia, 14026-040, Ribeirão Preto, SP. Tel.: (16)620-7602.E-mail: cleido@online.unaerp.bre cleidovasc@ hotmail.com. Maria Clotilde Rossetti Ferreira, doutora em Psicologia pela University of London, Reino Unido, é Professora titular do Depto. de Psicologia e Educação da FFCLRP-USP.

Endereço para correspondência: Depto de Psicologia e Educação da FFCLRP-USP, Campus da USP, Av. Bandeirantes, 3900, 14040-901, Ribeirão Preto, SP. E-mail: Mcferre@usp.br. 